\title{
Selective oxidation of benzyl alcohol with tert-butylhydroperoxide catalysed via Mn (II) 2, 2-bipyridine complexes immobilized over the mesoporous hexagonal molecular sieves (HMS)
}

\author{
VAHID MAHDAVI* and MAHDIEH MARDANI \\ Department of Chemistry, Surface Chemistry and Catalysis Division, Faculty of Sciences, Arak University, \\ Arak 38156-8-8349, Iran \\ e-mail: v-mahdavi@araku.ac.ir
}

MS received 21 December 2011; revised 14 May 2012; accepted 15 June 2012

\begin{abstract}
A series of $\mathrm{Mn}(\mathrm{II})$ bipy complexes with different loading of $\mathrm{Mn}^{2+}$ supported on HMS was prepared. These samples were characterized by Brunauer-Emmett-Teller (BET), X-ray diffraction (XRD), Thermogravimetric and Differential Scanning Calorimetry (TG-DSC), Ultraviolet and Visible spectra (UV-Vis) and Fourier transforms Infrared (FT-IR). The catalytic activity of the supported Mn(II)bipy complexes, [Mn(bipy) $\left.{ }_{2}\right]^{2+} / \mathrm{HMS}$ was evaluated in the oxidation of benzyl alcohol in the liquid phase using tert-butylhydroperoxide (TBHP) as an oxidant. The effects of $\mathrm{Mn}^{2+}$ loading and various solvents on the conversion and selectivity were studied. A second order function for the variation in catalytic activity with respect to the loading of $\mathrm{Mn}^{2+}$ ions in different catalyst samples was observed. The activity of the $\left[\mathrm{Mn}(\text { bipy })_{2}\right]^{2+} / \mathrm{HMS}$ catalyst differs with the type of the solvent and in this case, acetonitrile gives the best conversion results. The kinetic of benzyl alcohol oxidation was investigated at temperatures of $27,46,60,75$ and $90^{\circ} \mathrm{C}$ using $\left[\mathrm{Mn}(\text { bipy })_{2}\right]^{2+} / \mathrm{HMS}$ and excess TBHP. The order of reaction with respect to benzyl alcohol was determined to be pseudo-first order. The value of the apparent activation energy was also determined.
\end{abstract}

Keywords. $\quad\left[\mathrm{Mn}(\text { bipy })_{2}\right]^{2+} / \mathrm{HMS}$; benzyl alcohol oxidation; solvent effect; liquid phase oxidation; kinetic study.

\section{Introduction}

Selective catalytic oxidation of alcohols to carbonyls is one of the most important chemical transformations in industrial chemistry. Carbonyl compounds such as ketones and aldehydes are the precursors for many drugs, vitamins, and fragrances and they are also important intermediates for many complex syntheses. ${ }^{1,2}$ Benzaldehyde (BZH) has been widely applied in the manufacture of odorants, flavours and pharmaceutical intermediates as an important raw material. ${ }^{3}$ It is generally prepared either by hydrolysis of benzyl chloride or by oxidation of toluene which is a preferred process used in industry. Environmental concern has forced chemists to explore benign synthetic methods. Therefore, many new processes for BZH synthesis have emerged and catalytic oxidation of benzyl alcohol $(\mathrm{BZOH})$ to $\mathrm{BZH}$ has attracted much attention both in laboratory and chemical industry. ${ }^{4-12}$

*For correspondence
Several studies have been reported on the gas phase catalytic oxidation of $\mathrm{BZOH}$ to $\mathrm{BZH}$ with different catalyst and oxidant. ${ }^{13-19}$ However, in the vapour-phase oxidation process, the control of selectivity towards partial oxidation product is the main problem, and carbon oxides are also formed leading to very significant carbon loss. ${ }^{20}$ The carbon loss can be avoided by carrying out the catalytic oxidation of benzyl alcohol in a liquid phase at temperatures lower than that used in the vapour phase oxidation process. Therefore, oxidation of $\mathrm{BzOH}$ to $\mathrm{BzH}$ in liquid-phase is preferable.

We have recently reported the catalytic effect of some Schiff-base and bidentate Mn (II) complexes immobilized in the pore channels of mesoporous hexagonal molecular sieves (HMS), for oxidation of alcohols in the heterogeneous systems. ${ }^{21}$ It was found that immobilized $\left[\mathrm{Mn}(\text { bipy })_{2}\right]^{2+} / \mathrm{HMS}$ is an efficient catalyst for the oxidation of alcohols such as benzyl alcohol, $n$-hexanol and cyclohexanol. In the present study, the oxidation of benzyl alcohol kinetic, the effect of Mn loading on the catalytic activity and the effect of various solvents on the catalytic behaviour of Mn (II) 2, 2-bipyridine complexe immobilized in HMS ([Mn(bipy) $\left.)_{2}\right]^{2+} / \mathrm{HMS}$ ) were investigated. 


\section{Experimental}

\subsection{Materials}

All materials were of commercial reagent grade. The metal salt $\left(\mathrm{MnCl}_{2} \cdot 4 \mathrm{H}_{2} \mathrm{O}\right)$ and the ligand bipyridine (bipy), benzyl alcohol, tert-butylhydroperoxide (TBHP) $80 \%$ solution in di tert-butylperoxide were purchased from Merck chemical Company. The raw materials used in the synthesis of $\mathrm{Si}$-HMS samples were tetraethylorthosilicate (TEOS, 98\% Merck) Dodecylamine (DDA, 98\% Merck), hydrochloric acid ( $\mathrm{HCl}, 1$ $\mathrm{N})$, ethanol $(\mathrm{EtOH})$, water and all solvents used: acetonitrile, toluene, THF and ethanol were of the highest commercial quality, which were supplied by Merck Company, and used without further purification.

\subsection{Preparation of catalysts}

2.2a Synthesis of Si-HMS and $M n^{2+} / H M S$ catalysts: $\mathrm{Si}-\mathrm{HMS}$ was synthesized according to literature procedures. ${ }^{21-23}$ A solution (A) was prepared by adding $21 \mathrm{~g}$ of ethanol to $15 \mathrm{~g}$ of TEOS; the resulting solution was stirred for $30 \mathrm{~min}$. Another solution (B) was prepared by adding $46 \mathrm{~g}$ of water and $1.4 \mathrm{ml}$ of $1 \mathrm{~N} \mathrm{HCl}$ to $3.5 \mathrm{~g}$ of DDA and stirring for about $5 \mathrm{~min}$. Solution (A) and (B) were mixed together and stirred moderately at room temperature for $18 \mathrm{~h}$. The molar gel composition of the final reaction mixture was: $\mathrm{SiO}_{2}: 0.27 \mathrm{DDA}: 0.02 \mathrm{HCl}$ : 6.5 EtOH: $37 \mathrm{H}_{2} \mathrm{O}$.

The final gels were stirred at room temperature for $18 \mathrm{~h}$. Subsequently, the products were filtered, washed thoroughly with deionized water, dried at $353 \mathrm{~K}$ and calcined at $773 \mathrm{~K}$ for $6 \mathrm{~h}$ in dry air.

The samples of manganese impregnated Si-HMS with different metal loading some as 86.5, 64.7, 43.25, 21.6 and $10.8 \mathrm{mg} \mathrm{Mn} / 1 \mathrm{~g}$ HMS were prepared by dispersing $2 \mathrm{~g} \mathrm{Si-HMS}$ in a solution of 0.626 , $0.468,0.313,0.156$ and $0.077 \mathrm{~g}$ of the metal salt $\left(\mathrm{MnCl}_{2} \cdot 4 \mathrm{H}_{2} \mathrm{O}\right)$ in $25 \mathrm{ml}$ water, respectively. The mixture was stirred and evaporated at room temperature until it was dried.

2.2b Preparation of Mn (II) 2, 2-bipyridine complexes/HMS catalysts: In this section, the HMSsupported Mn (II) 2, 2-bipyridine complexes samples with loading of 86.5, 64.7, 43.25, 21.6 and $10.8 \mathrm{mg}$ $\mathrm{Mn} / 1 \mathrm{~g}$ HMS was synthesized. In a typical procedure, about $1 \mathrm{~g}$ of each $\mathrm{Mn}^{2+} / \mathrm{HMS}$ sample which was prepared in previous step was added to a suitable amount of solution of ligand 2, 2'-bipyridine (bipy) in $100 \mathrm{ml}$ methanol. The suspensions were then stirred under reflux condition for $24 \mathrm{~h}$. The solid was separated, washed with methanol and then soxhlet extracted with mixture of 1:1 methanol and chloroform in order to remove unreacted ligand. It was then dried at $125^{\circ} \mathrm{C}$ under nitrogen atmosphere for several hours. ${ }^{24}$ The contents of manganese in the samples were determined by atomic absorption spectroscopy (AAS) using a perkin-Elmer Analyst instrument, after extraction of $\mathrm{Mn}$ from the catalysts samples in $\mathrm{HNO}_{3}$ and $\mathrm{HF}$ acids and the samples were labelled as $\left[\mathrm{Mn}(\text { bipy })_{2}\right]^{2+}(86.5) / \mathrm{HMS},\left[\mathrm{Mn}(\text { bipy })_{2}\right]^{2+}(64.7) / \mathrm{HMS}$, $\left[\mathrm{Mn}(\text { bipy })_{2}\right]^{2+}(43.2) / \mathrm{HMS},\left[\mathrm{Mn}(\text { bipy })_{2}\right]^{2+}(21.6) / \mathrm{HMS}$ and $\left[\mathrm{Mn}(\text { bipy })_{2}\right]^{2+}(10.8) / \mathrm{HMS}$.

In the next step, these solids are used in liquid phase to catalyse the oxidation of benzyl alcohol by TBHP.

\subsection{Catalyst characterization}

The surface area of Si-HMS and the Mn (II) 2, 2bipyridine complexes supported on HMS were measured using the Brunauer-Emmett-Teller (BET) method on a Micromeritics ASAP 2010 instrument using $\mathrm{N}_{2}$ as the adsorbent. The structure of the Si-HMS was studied by X-ray diffraction (XRD) experiments. A Philips model PW 1800 diffractometer with $\mathrm{Cu} \mathrm{K} \alpha$ radiation and Ni filter was used to collect the X-ray data. Thermal stability of samples was studied with thermogravimetric and differential scanning calorimetry (TG-DSC) using a PL-1500 instrument. Nitrogen gas was used as carrier gas for TGA experiment and the flow rate of $\mathrm{N}_{2}$ was about $40 \mathrm{ml} / \mathrm{min}$. The heating rate was set at $10^{\circ} \mathrm{C} / \mathrm{min}$ with scans from ambient temperature to $650^{\circ} \mathrm{C}$. The infrared spectra of the catalysts were taken as $\mathrm{KBr}$ pellets on a Galaxy-5000 Fourier transform IR (FT-IR) spectrometer. The UV-Vis spectra were obtained using a Perkin-Elmer Model Lambda 2 spectrophotometer.

\subsection{Oxidation of benzyl alcohol}

In a typical procedure, a mixture of $0.2 \mathrm{~g}$ $\left.[\mathrm{Mn} \text { (bipy })_{2}\right]^{2+}(86.5) / \mathrm{HMS}$ catalyst with the grain size of 200-230 mesh containing $86.5 \mathrm{mg} \mathrm{Mn} / \mathrm{g}$ HMS, $15 \mathrm{~mL}$ solvent (acetonitrile) and $30 \mathrm{mmol}$ of benzyl alcohol was stirred in a three-necked flask under nitrogen atmosphere at $50^{\circ} \mathrm{C}$ for $30 \mathrm{~min}$. The stirring rate of the solution was set at $750 \mathrm{cycle} / \mathrm{min}$. Then $30 \mathrm{mmol}$ of the oxidant (TBHP) was added to the solution and the mixture was refluxed for $8 \mathrm{~h}$ under nitrogen atmosphere. After filtration, the reaction mixture was analysed by GC. A GC-MS of model Thermo Finnigan (60 m, RTX-1 column) was used for the identification of products and a GC (Perkin Elmer Model 1800) was 
used for the products analysis. The GC was equipped with a flame ionization detector (FID) connected to a $3 \% \mathrm{OV}-17$ column with length of $2.5 \mathrm{~m}$ and diameter of $1 / 8$ inch.

\section{Results and discussion}

\subsection{Catalyst characterization}

The BET surface area values and pore diameter of catalysts are given in table 1 . As shown in table 1, the pore diameter for the HMS immobilized catalysts compared to the native support do not differ much and there is a significant decrease in the surface area of the immobilized catalysts. This change in the surface area is as one would expect. By immobilizing the Mn (II) 2, 2bipyridine complex onto the support, the surface of the support where nitrogen can adsorb becomes less and causes the decrease in the total volume of nitrogen that can be adsorbed. The expected decrease in the surface area was observed for this sample showing that immobilization of the Mn complex was successful.

The small-angle XRD pattern of the HMS sample is shown in figure 1, which is similar to the XRD pattern reported by Tanev et al. ${ }^{22}$ The HMS support shows three peaks at $2 \theta=0.77^{\circ}, 2.2^{\circ}$, and $4.2^{\circ}$, corresponding to the diffraction of (100), (110), and (200) planes. These peaks are characteristics of the hexagonally ordered structure of HMS. ${ }^{25}$ The hexagonal array (HMS, MCM-41) gives a rather broad and poorly defined X-ray diffraction pattern, and low angles $(\theta<$ $1^{\circ}$ ) are necessary to observe the (100) reflection, which is usually the strongest peak. This in itself is an indication that large features have been created because the Bragg equation shows that the $d_{100}$ interlattice spacing is more than $4.4 \mathrm{~nm}$ when $\theta$ is less than $1^{\circ}$.

The FT-IR spectra of HMS, $\mathrm{Mn}^{2+} / \mathrm{HMS}$ and $\left[\mathrm{Mn}(\text { bipy })_{2}\right]^{2+} / \mathrm{HMS}$ samples are shown in figure 2 . From figure 2 , it is evident that there is no significant difference among the FT-IR spectra ob-

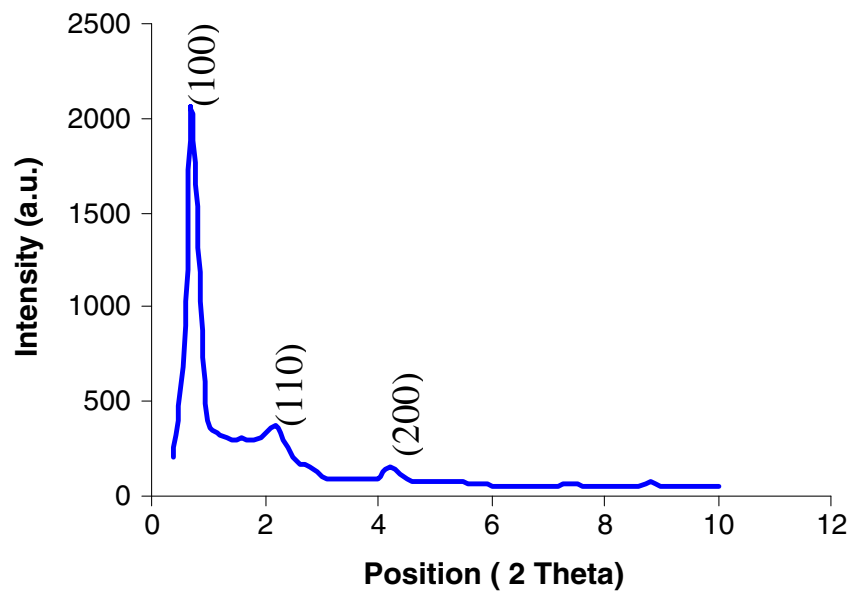

Figure 1. Small-angle XRD pattern for the HMS sample.

tained from HMS and $\mathrm{Mn}^{2+} / \mathrm{HMS}$ samples and the characteristic $\mathrm{Mn}$ peaks were found at 761.93 and $864.16 \mathrm{~cm}^{-1}$. Some characteristic bands associated with $\left[\mathrm{Mn}(\text { bipy })_{2}\right]^{2+}$ complex, such as: $v(\mathrm{C}-\mathrm{H})$ aromatic vibrations at 3095 and $3061 \mathrm{~cm}^{-1}, v(\mathrm{C}=\mathrm{N})$ vibration at $1489 \mathrm{~cm}^{-1}, v(\mathrm{C}=\mathrm{C})$ vibrations of phenyl ring at 1313 and $1421 \mathrm{~cm}^{-1}, v(\mathrm{Mn}-\mathrm{N})$ vibration at $775 \mathrm{~cm}^{-1}$ were also observed. ${ }^{26}$

The UV-Vis spectra of $\left[\mathrm{Mn}(\text { bipy })_{2}\right]^{2+} / \mathrm{HMS}$ and $\left[\mathrm{Mn}(\text { bipy })_{2}\right]^{2+}$ samples are shown in figure 3 . As figure 3 shows, the UV-Vis spectra of $\left[\mathrm{Mn}(\text { bipy })_{2}\right]^{2+}$ complexe and $\left[\mathrm{Mn}(\text { bipy })_{2}\right]^{2+} / \mathrm{HMS}$ are very similar with two strong bands. More specifically, the two bands near 200-216 nm are attributed to the $\pi-\pi *$ transition of the benzene ring of bipyridine, and the $n-\pi *$ transition of the $\mathrm{C}=\mathrm{N}$ bond, respectively, ${ }^{27}$ while the third band near 359-362 nm, as the most characteristic adsorption band of $\left[\mathrm{Mn}(\text { bipy })_{2}\right]^{2+}$ complex is due to the metal to ligand charge transfer (MLCT). ${ }^{28}$ The FT-IR and the UV-Vis spectra indicate that Mn(II)-bipy complex has been successfully in situ synthesized inside the pores or over the external surfaces of HMS.

Figure 4 shows TG-DSC results for $\left[\mathrm{Mn}(\text { bipy })_{2}\right]^{2+}(86.5) / \mathrm{HMS}$ sample. The thermal analysis occurs in the five steps: Steps 1 to 4 (endothermic),

Table 1. The BET surface area values and average pore diameter of catalysts with different Mn complex loading.

\begin{tabular}{lccc}
\hline Catalyst & $\begin{array}{c}\mathrm{Mn}^{2+} \text { loading } \\
(\mathrm{mg} \mathrm{Mn} / \mathrm{g} \text { HMS })\end{array}$ & $\begin{array}{c}\text { Surface } \\
\text { area }\left(\mathrm{m}^{2} / \mathrm{g}\right)\end{array}$ & $\begin{array}{c}\text { Average pore } \\
\text { diameter }(\AA)\end{array}$ \\
\hline $\mathrm{HMS}$ & 0 & 993 & 36.2 \\
{$\left[\mathrm{Mn}(\text { bipy })_{2}\right]^{2+}(10.8) / \mathrm{HMS}$} & 10.8 & 825 & 33.7 \\
{$\left[\mathrm{Mn}(\text { bipy })_{2}\right]^{2+}(21.6) / \mathrm{HMS}$} & 21.6 & 752 & 33.1 \\
{$\left[\mathrm{Mn}(\text { bipy })_{2}\right]^{2+}(43.2) / \mathrm{HMS}$} & 43.2 & 721 & 32.2 \\
{$\left[\mathrm{Mn}(\text { bipy })_{2}\right]^{2+}(64.7) / \mathrm{HMS}$} & 64.7 & 692 & 33.5 \\
{$\left[\mathrm{Mn}(\text { bipy })_{2}\right]^{2+}(86.5) / \mathrm{HMS}$} & 86.5 & 663 & 32.4 \\
\hline
\end{tabular}




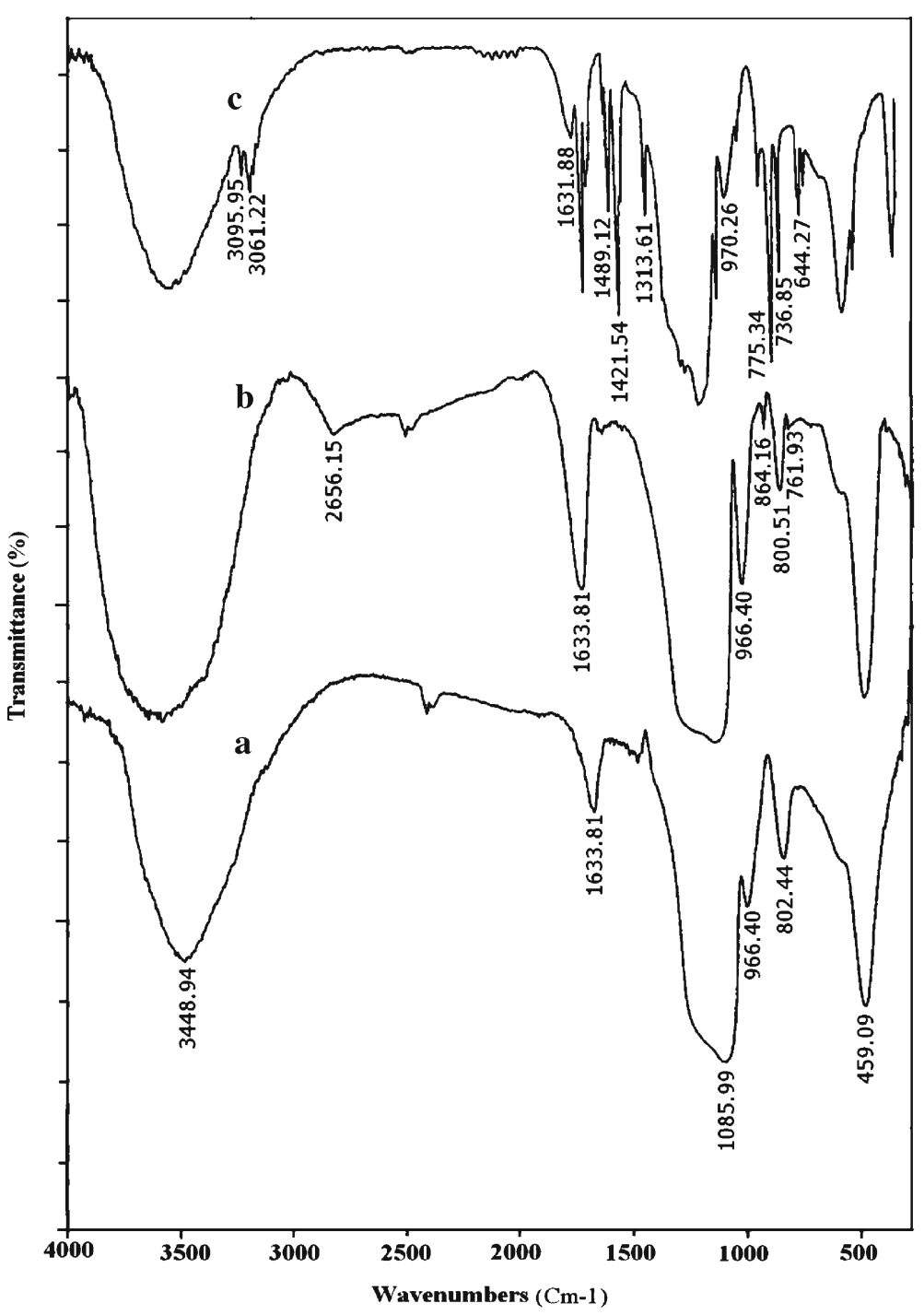

Figure 2. FT-IR spectra of (a) HMS, (b) $\mathrm{Mn}^{2+} / \mathrm{HMS}$ containing $86.5 \mathrm{mg} \mathrm{Mn} / 1 \mathrm{~g} \mathrm{HMS}$ and (c) $\left[\mathrm{Mn}(\mathrm{bipy})_{2}\right]^{2+} / \mathrm{HMS}$.

in the ranges of $25-396.9^{\circ} \mathrm{C}$, are involved with the water loss and the dehydroxylation of the HMS surface (7.86\% weight loss of the sample). In the 5th step (exothermic) between $397-561.6^{\circ} \mathrm{C}$, the ligand groups of $\left[\mathrm{Mn}(\text { bipy })_{2}\right]^{2+}(86.5) / \mathrm{HMS}$ sample are decomposed, and perhaps $\mathrm{CO}, \mathrm{CO}_{2}$ and $\mathrm{NOx}$ gases are released (4.1\%, weight loss of the sample). Therefore, the total weight loss of the sample is $11.96 \%$ and the results of TGA indicate that the $\left[\mathrm{Mn}(\text { bipy })_{2}\right]^{2+}$ complex immobilized HMS sample is thermally stable in the reaction temperature range of $27-90^{\circ} \mathrm{C}$.

\subsection{Oxidation of benzyl alcohol with TBHP on the $\left[\mathrm{Mn}(\text { bipy })_{2}\right]^{2+} / \mathrm{HMS}$ catalysts}

Oxidation of benzyl alcohol was studied exclusively for loading effect, solvent effect and kinetic measurements and results of the study are as follows. 3.2a Effect of loading of $\mathrm{Mn}^{2+}$ on the activity of catalysts: The results of the oxidation of benzyl alcohol in the presence of TBHP and without catalyst,

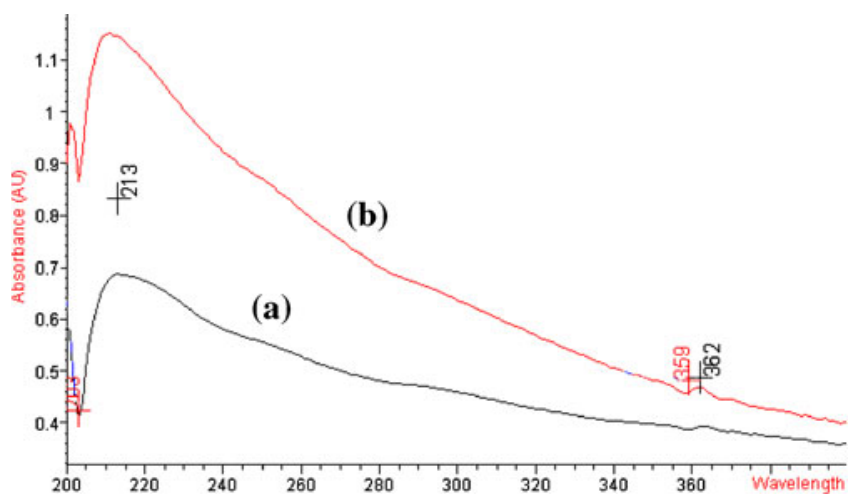

Figure 3. UV-VIS spectra of the (a) $\left[\mathrm{Mn}(\text { bipy })_{2}\right]^{2+} / \mathrm{HMS}$ and $(\mathbf{b})\left[\mathrm{Mn}(\text { bipy })_{2}\right]^{2+}$. 


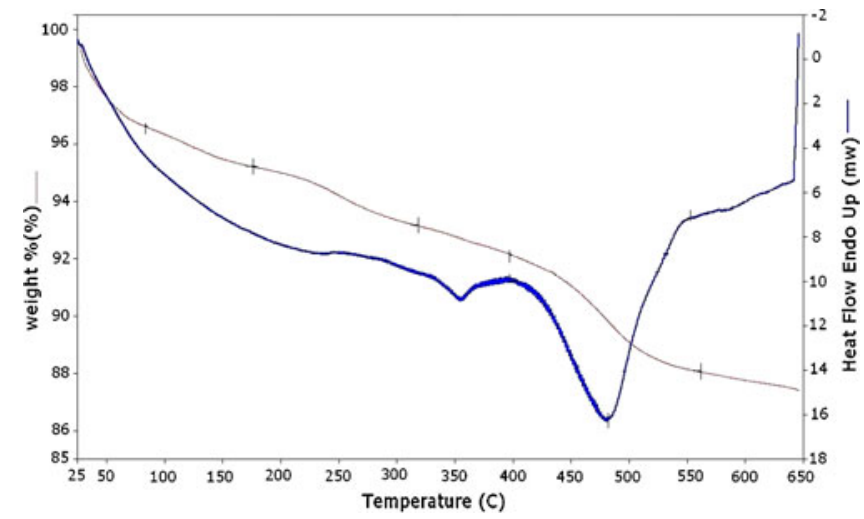

Figure 4. Thermogravimetry and differential scanning calorimetry diagram of $\left[\mathrm{Mn}(\text { bipy })_{2}\right]^{2+}(86.5) / \mathrm{HMS}$ sample. Steps 1 to 4 (endothermic), in the range of $25-396.9^{\circ} \mathrm{C}$, elimination of humidity and the dehydroxylation of the HMS surface; step 5 (exothermic), in the range of $397-561.6^{\circ} \mathrm{C}$, elimination of the ligand groups of $\left[\mathrm{Mn}(\mathrm{bipy})_{2}\right]^{2+} / \mathrm{HMS}$ sample.

Si-HMS and $\left[\mathrm{Mn}(\text { bipy })_{2}\right]^{2+} / \mathrm{HMS}$ samples with loading of 86.5, 64.7, 43.2, 21.6 and $10.8 \mathrm{mg} \mathrm{Mn} / 1 \mathrm{~g} \mathrm{HMS}$, are shown in table 2 . All reactions were conducted at reflux temperature $\left(90^{\circ} \mathrm{C}\right)$ for $8 \mathrm{~h}$ with $0.2 \mathrm{~g}$ of the catalyst, $15 \mathrm{~mL}$ solvent, acetonitrile, $30 \mathrm{mmol}$ of the benzyl alcohol and $30 \mathrm{mmol}$ TBHP. In all the reactions, conversion percentage was calculated with respect to the substrate (benzyl alcohol). In the absence of any catalyst, benzyl alcohol conversion is lower than $4.3 \%$. HMS gives a benzyl alcohol conversion around $15 \%$. The result shows that the reactions with $\left[\mathrm{Mn}(\text { bipy })_{2}\right]^{2+} / \mathrm{HMS}$ catalysts have relatively high conversion percentage compare to the HMS sample or blank reaction. In addition, $\left[\mathrm{Mn}(\text { bipy })_{2}\right]^{2+}(86.5) /$ HMS catalyst has higher conversion percentage with respect to the other samples with

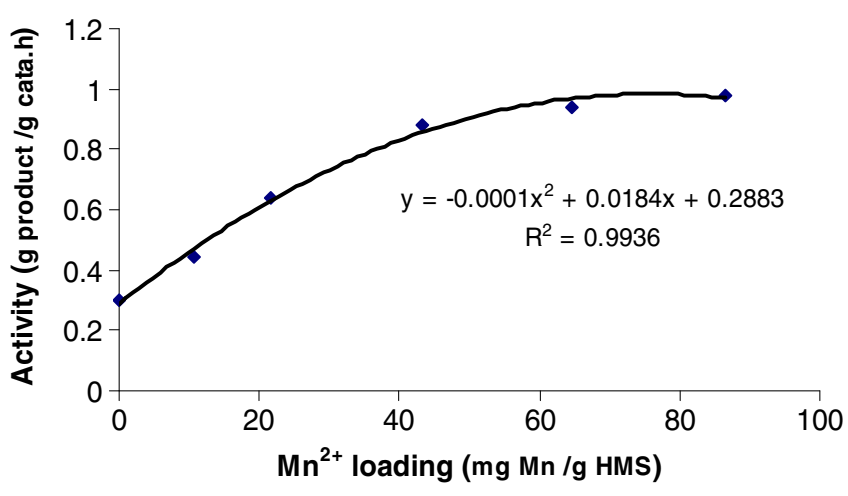

Figure 5. Activity of $\left[\mathrm{Mn}(\text { bipy })_{2}\right]^{2+} / \mathrm{HMS}$ catalyst as a function of $\mathrm{Mn}^{2+}$ loading. Reaction condition: $0.2 \mathrm{~g}$ $\left[\mathrm{Mn}(\text { bipy })_{2}\right]^{2+} / \mathrm{HMS}$ catalyst with the grain size of $200-230$ mesh; benzyl alcohol $30 \mathrm{mmol}$; TBHP $30 \mathrm{mmol}$; $15 \mathrm{ml}$ acetonitrile; Reflux temperature $\left(90^{\circ} \mathrm{C}\right)$; reaction time $8 \mathrm{~h}$, the stirring rate of the reaction mixture $750 \mathrm{cycle} / \mathrm{min}$.

64.7, 43.2, 21.6 and 10.8 of $\mathrm{mg} \mathrm{Mn} / 1 \mathrm{~g}$ HMS. Table 2 shows that the selectivity of all catalysts is independent of the loading of $\mathrm{Mn}$ and with increasing the loading of Mn on the HMS, the selectivity with respect to benzaldehyde remains constant.

The data from table 2 are used to plot the figure 5 in which variation of activity with respect to the loading of $\mathrm{Mn}^{2+}$ in catalysts is shown. A second order function for the variation in catalytic activity with respect to the loading of $\mathrm{Mn}^{2+}$ ions in different catalyst samples was observed as follows:

$$
\mathrm{Y}=-0.0001 \mathrm{X}^{2}+0.0184 \mathrm{X}+0.2883
$$

where $\mathrm{X}$ stands for loading of Mn and $\mathrm{Y}$ is the activity of catalyst sample.

Table 2. Oxidation of benzyl alcohol with TBHP in the presence of $\left[\mathrm{Mn}(\mathrm{bipy})_{2}\right]^{2+} / \mathrm{HMS}$ catalyst. Reaction condition: $0.2 \mathrm{~g}\left[\mathrm{Mn}(\text { bipy })_{2}\right]^{2+} / \mathrm{HMS}$ catalyst with the grain size of 200-230 mesh; benzyl alcohol $30 \mathrm{mmol}$; TBHP $30 \mathrm{mmol}$; $15 \mathrm{~mL}$ acetonitrile; reflux temperature $\left(90^{\circ} \mathrm{C}\right)$; reaction time $8 \mathrm{~h}$, the stirring rate of the reaction mixture $750 \mathrm{cycle} / \mathrm{min}$.

\begin{tabular}{lccccc}
\hline Entry & Catalyst & $\begin{array}{c}\mathrm{Mn}^{2+} \text { loading }^{\mathrm{a}} \\
(\mathrm{mg} \mathrm{Mn} / \mathrm{g} \mathrm{HMS})\end{array}$ & $\begin{array}{c}\text { Conversion }^{\mathrm{b}} \\
(\%)\end{array}$ & $\begin{array}{c}\mathrm{TOF}^{\mathrm{c}} \\
\left(\mathrm{h}^{-1}\right)\end{array}$ & $\begin{array}{c}\text { Selectivity } \\
\text { benzaldehyde (\%) }\end{array}$ \\
\hline 1 & - & 0 & $4.30^{\mathrm{e}}$ & - & 100 \\
2 & $\mathrm{HMS}$ & 0 & 15.10 & - & 100 \\
3 & {$\left[\mathrm{Mn}(\text { bipy })_{2}\right]^{2+}(10.8) / \mathrm{HMS}$} & 10.8 & 22.31 & 21.28 & 100 \\
4 & {$\left[\mathrm{Mn}(\text { bipy })_{2}\right]^{2+}(21.6) / \mathrm{HMS}$} & 21.6 & 32.22 & 15.37 & 100 \\
5 & {$\left[\mathrm{Mn}(\text { bipy })_{2}\right]^{2+}(43.2) / \mathrm{HMS}$} & 43.2 & 44.30 & 10.56 & 100 \\
6 & {$\left[\mathrm{Mn}(\text { bipy })_{2}\right]^{2+}(64.7) / \mathrm{HMS}$} & 64.7 & 47.41 & 7.55 & 100 \\
7 & {$\left[\mathrm{Mn}(\text { bipy })_{2}\right]^{2+}(86.5) / \mathrm{HMS}$} & 86.5 & 49.21 & 5.86 & 100 \\
\hline
\end{tabular}

${ }^{\mathrm{a}}$ The contents of Mn were determined by AAS; ${ }^{\mathrm{b}}$ Conversion $=$ (mol. of benzyl alcohol reacted $/ \mathrm{mol}$. of benzyl alcohol in the feed) $\times 100 ;{ }^{c}$ Turnover frequency (TOF) was calculated from benzyl alcohol amount $(\mathrm{mmol}) \cdot$ its conversion $(\%) /\left(\right.$ catalyst amount $(\mathrm{g}) \cdot \mathrm{Mn}$ loading $\left(\mathrm{mmol} \mathrm{g}^{-1}\right) \cdot$ reaction time $\left.(\mathrm{h})\right)$; ${ }^{\mathrm{d}}$ Selectivity $=($ mol. of benzyl alcohol converted to benzaldehyde/mol. of alcohol reacted $) \times 100 ;{ }^{\mathrm{e}}$ Without catalyst 
In fact, these samples were active in this reaction, and their activities were basically proportional to their $\mathrm{Mn}$ loadings. But there was the restrictions effect on the diffusion of substrate and product through the channels of the solid. Moreover, this mass transfer resistance gradually increased with the Mn-complex loadings inside the support, which was confirmed from the data of turnover frequency listed in table 2.

On the $\left[\mathrm{Mn}(\text { bipy })_{2}\right]^{2+}(86.5) / \mathrm{HMS}$ catalyst, the conversion of benzyl alcohol was $49.21 \%$ and the selectivity of benzaldehyde was $100 \%$. Therefore, $\left.[\mathrm{Mn} \text { (bipy })_{2}\right]^{2+}(86.5) / \mathrm{HMS}$ may be a better catalyst with respect to the all other catalysts listed in table 2 .

3.2b Effect of solvent: In these experiments the solvent was changed for each run while the other conditions, $\left(0.2 \mathrm{~g}\right.$ of the $\left[\mathrm{Mn}(\text { bipy })_{2}\right]^{2+}(86.5) / \mathrm{HMS}$ catalyst containing $86.5 \mathrm{mg} \mathrm{Mn} / \mathrm{g}$ HMS, $30 \mathrm{mmol}$ benzyl alcohol, $30 \mathrm{mmol}$ TBHP, the rotation rate of the reaction mixture 750 cycle/min and reaction temperature, $70^{\circ} \mathrm{C}$ for $8 \mathrm{~h}$ ) remain the same. The solvent has been varied from polar protic to polar non-protic one and extended to non-polar solvent. The results of benzyl alcohol conversion with the various solvents are shown in table 3 .

As demonstrated by table 3 , the behaviour of benzyl alcohol oxidation in various solvents is strikingly different. Acetonitrile gives the best conversion results (table 3), followed by toluene. From the observation, we concluded that the selectivity toward benzaldehyde, as the only product, was constant in various solvents. The reduction of the conversion percentage of benzyl alcohol in toluene, THF and ethanol may be explained by the low solubility of TBHP in a non-polar solvent by which the reaction could not proceed. Acetonitrile is a polar solvent with a very high dielectric constant, it may readily dissolve TBHP along with the benzyl alcohol and consequently can direct the reactants in such a way that properly be adsorbed on the catalyst surface and increasing the efficiency of the conversion. Highly polar solvents like acetonitrile may facilitate formation of active oxygen species and thereby enhance the catalytic activity. The best conversion for benzyl alcohol in the acetonitrile as a solvent is shown in table 3 .

3.2c Kinetics of reaction: The depletion of benzyl alcohol concentration in the presence of excess TBHP in the acetonitrile as a solvent was monitored and plotted with respect to time (figure $6 \mathrm{a}$ ). The reaction was carried out in the presence of $15 \mathrm{ml}$ acetonitrile, $10 \mathrm{mmol}$ benzyl alcohol, $150 \mathrm{mmol}$ TBHP, $0.2 \mathrm{~g}$ of $\left[\mathrm{Mn}(\text { bipy })_{2}\right]^{2+}(85.6) / \mathrm{HMS}$ catalyst with the grain size of 200-230 mesh containing $86.5 \mathrm{mg} \mathrm{Mn} / \mathrm{g}$ HMS. The rotation rate of the reaction mixture was $750 \mathrm{cycle} / \mathrm{min}$ at $90^{\circ} \mathrm{C}$ in a two-necked round-bottom flask. Samples of $0.3 \mu \mathrm{l}$ of reaction mixture were drawn out at regular intervals and analysed by GC. The rate expression ${ }^{29}$ may be written as

$$
\begin{gathered}
\text { Rate }=\mathrm{k}[\mathrm{BZOH}]^{\mathrm{n}}[\mathrm{TBHP}]^{\mathrm{m}} \text { and } \\
\text { Rate }=-\mathrm{d}(\mathrm{BZOH}) / \mathrm{d}(\mathrm{t}),
\end{gathered}
$$

where $\mathrm{BZOH}$ stands for benzyl alcohol, $\mathrm{n}$ is the order of reaction with respect to benzyl alcohol, $\mathrm{m}$ is the order of reaction with respect to TBHP, and $\mathrm{k}$ is the rate constant. In order to find $n$, the rate expression (1) may be rewritten as

$$
\text { Rate }=\mathrm{k}^{\prime}[\mathrm{BZOH}]^{\mathrm{n}} \quad \text { if }
$$$$
[\mathrm{TBHP}]^{\mathrm{m}}=\text { constant, because TBHP is in excess. }
$$

Table 3. Effect of solvents on oxidation of benzyl alcohol with TBHP in the presence of $\left[\mathrm{Mn}(\text { bipy })_{2}\right]^{2+} / \mathrm{HMS}$. Reaction condition: $0.2 \mathrm{~g}$ $\left.[\mathrm{Mn} \text { (bipy) }]_{2}\right]^{2+}(86.5) / \mathrm{HMS}$ catalyst containing $86.5 \mathrm{mg} \mathrm{Mn} / 1 \mathrm{~g}$ HMS with the grain size of 200-230 mesh; benzyl alcohol $30 \mathrm{mmol}$; TBHP $30 \mathrm{mmol}$; reaction temperature $\left(70^{\circ} \mathrm{C}\right)$; reaction time $8 \mathrm{~h}$, the stirring rate of the reaction mixture $750 \mathrm{cycle} / \mathrm{min}$.

\begin{tabular}{lccccc}
\hline Solvent & $\begin{array}{c}\text { Protic/ } \\
\text { aprotic }\end{array}$ & $\begin{array}{c}\text { Dielectric } \\
\text { constant }\end{array}$ & $\begin{array}{c}\text { Dipole } \\
\text { moment (D) }\end{array}$ & $\begin{array}{c}\text { Conversion } \\
(\%)\end{array}$ & $\begin{array}{c}\text { Selectivity } \\
(\%)\end{array}$ \\
\hline Acetonitrile & Aprotic & 37.5 & 3.92 & 40.21 & 100 \\
Toluene & Aprotic & 2.4 & 0 & 26.32 & 100 \\
THF & Aprotic & 7.52 & 3.89 & 10.21 & 100 \\
Ethanol & Protic & 24.5 & 1.69 & 7.66 & 100 \\
\hline
\end{tabular}

Conversion $=($ mol. of benzyl alcohol reacted $/ \mathrm{mol}$. of benzyl alcohol in the feed) $\times 100$.

Selectivity $=$ (mol. of benzyl alcohol converted to benzaldehyde/mol. of alcohol reacted) $\times 100$ 

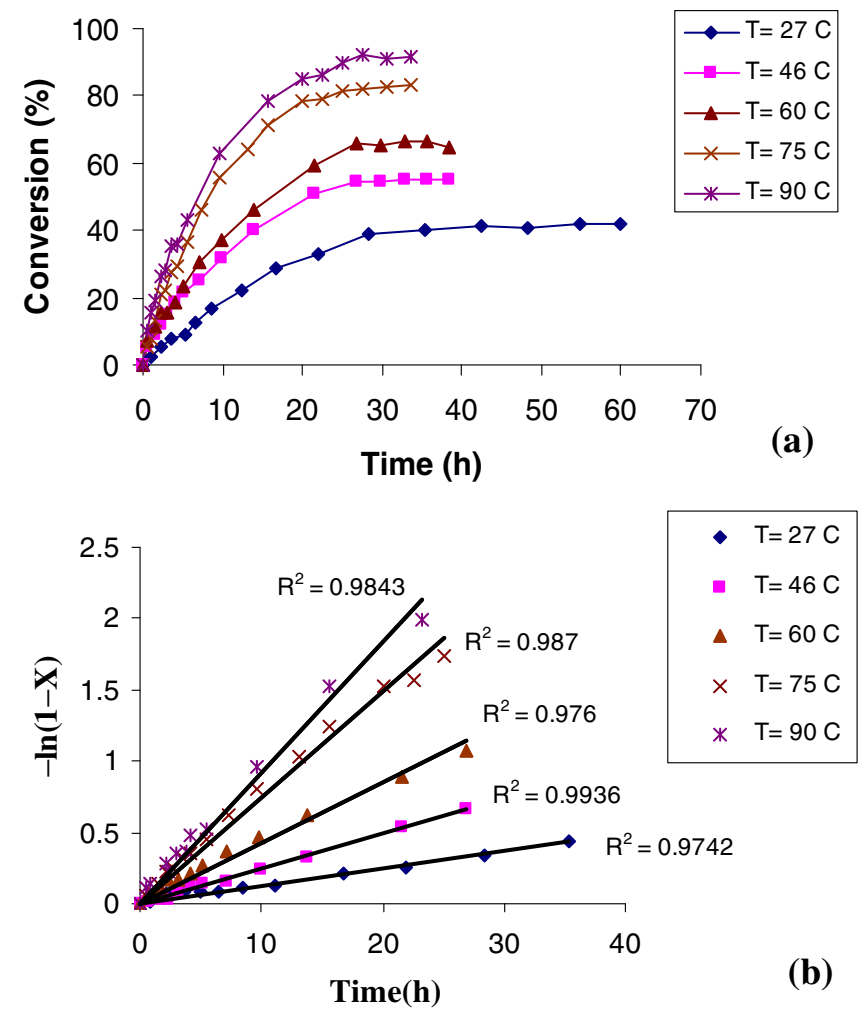

Figure 6. (a) Conversion of benzyl alcohol as a function of time at 27, 46, 60, 75 and $90^{\circ} \mathrm{C}$ with $\left[\mathrm{Mn}(\text { bipy })_{2}\right]^{2+}(86.5) / \mathrm{HMS}$ catalyst in the presence of excess TBHP. (b) Pseudo-first-order kinetics of benzyl alcohol oxidation at 27, 46, 60, 75 and $90^{\circ} \mathrm{C}$ with $\left[\mathrm{Mn}(\text { bipy })_{2}\right]^{2+}(86.5) / \mathrm{HMS}$ catalyst in the presence of excess TBHP. Reaction condition: $0.2 \mathrm{~g}\left[\mathrm{Mn}(\text { bipy })_{2}\right]^{2+}(86.5) / \mathrm{HMS}$ catalyst with the grain size of 200-230 mesh; benzyl alcohol $10 \mathrm{mmol}$; TBHP $150 \mathrm{mmol} ; 15 \mathrm{ml}$ acetonitrile; the stirring rate of the reaction mixture 750 cycle/min.

Combining expressions (2) and (3) give rise to

$$
-\mathrm{d}(\mathrm{BZOH}) / \mathrm{d}(\mathrm{t})=\mathrm{k}^{\prime}[\mathrm{BZOH}]^{\mathrm{n}} .
$$

If $n=1$ on integrating expression (4), from the initial concentration at initial time to the final concentration at the final time $t$, the expression (4) can be written as

$$
-\ln (1-\mathrm{X})=\mathrm{k}^{\prime} \mathrm{t},
$$

$\mathrm{X}$ is the conversion of benzyl alcohol after time $t$.

A plot of $-\ln (1-X)$ with respect to time is linear and showing a pseudo-first-order dependence on the benzyl alcohol (figure 6b).

3.2d Effect of temperature: Oxidation of benzyl alcohol was carried out at $27,46,60,75$ and $90^{\circ} \mathrm{C}$ in the same reaction condition and the results were shown in figures $6 a$ and $b$. The effect of temperature on the reaction rate showed that the catalytic activity strongly increased with the increasing of the reaction temperature and the selectivity toward benzaldehyde is constant. According to the figure $6 \mathrm{a}$, the time for $50 \%$ conversion of benzyl alcohol changed from $21 \mathrm{~h}$ at $46^{\circ} \mathrm{C}$ to $8 \mathrm{~h}$ at $90^{\circ} \mathrm{C}$. The pseudo-first-order rate constants of the reactions at the different temperatures are found from the slope of the plots (figure 6b). The plots of rate constant vs $\mathrm{T}$ (figure $7 \mathrm{a}$ ) and $\ln$ (rate constant) vs $1 / \mathrm{T}$ (Arrhenius plot) (figure $7 \mathrm{~b}$ ) were drawn. The value of the apparent activation energy (Ea) was evaluated from the slope of the plot to be $30.13 \mathrm{~kJ} \mathrm{~mol}^{-1}$. In fact, this value can probably suggest that no interference of diffusional limitations is existed.

Metal-catalysed oxidation involving alkyl peroxides may proceed either through a homolytic or heterolytic mechanism. Transition metal salts of $\mathrm{Co}, \mathrm{Mn}, \mathrm{Fe}, \mathrm{Cu}$, or the metal oxides are normally involved in homolytic cleavage. ${ }^{1}$ Therefore, we suggested that the oxidation pathway may be as follows

$$
\begin{gathered}
\mathrm{MnL}_{2}^{\mathrm{n}}+t \text {-butOOH } \rightarrow t \text {-butO }+\mathrm{MnL}_{2}^{\mathrm{n}} \mathrm{OH}, \\
\mathrm{MnL}_{2}^{\mathrm{n}}+t \text {-butOOH } \rightarrow t \text {-butOO }+\mathrm{MnL}_{2}^{\mathrm{n}}+\mathrm{H},
\end{gathered}
$$

$$
t \text {-butOO }+\mathrm{RCH}_{2}-\mathrm{OH} \rightarrow t \text {-butOOH }+\mathrm{RCH}-\mathrm{OH},
$$

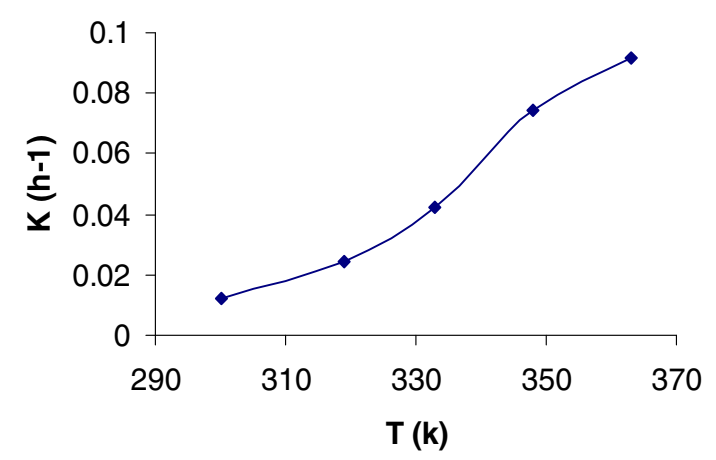

(a)

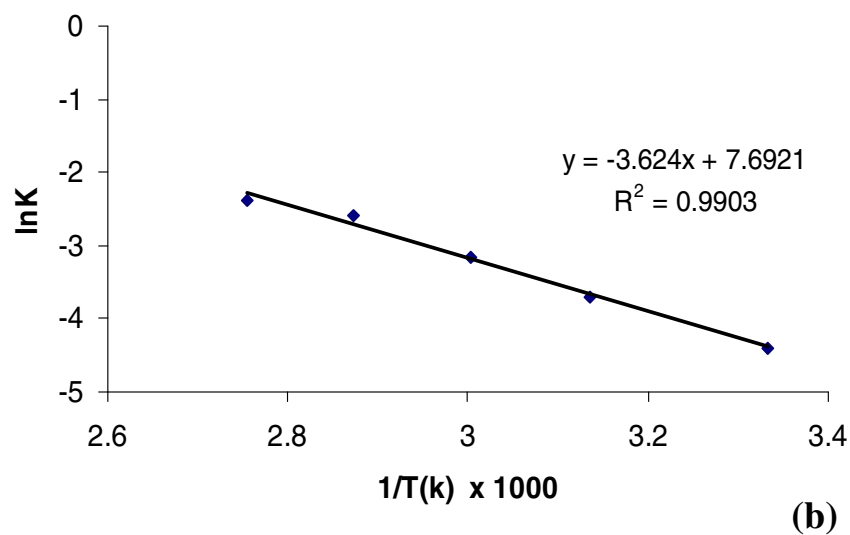

Figure 7. (a) Effect of temperature on the rate constant of the oxidation of benzyl alcohol. (b) Arrhenius plot. 


$$
t \text {-butO }+\mathrm{RCH}_{2}-\mathrm{OH} \rightarrow t-\text { butOH }+\mathrm{RCH}-\mathrm{OH},
$$

$$
\mathrm{RCH}-\mathrm{OH} \rightarrow \mathrm{RCHO}+\mathrm{H} .
$$

where $\mathrm{RCH}_{2}-\mathrm{OH}=$ benzyl alcohol, $\mathrm{RCHO}=$ benzaldehyde.

3.2e Catalyst recycling and leaching: The leaching of the catalyst was tested by filtering the catalyst during the reaction and studying the catalytic activity of the filtrate. In this study, a mixture of $0.2 \mathrm{~g}$ catalyst $\left[\mathrm{Mn}(\text { bipy })_{2}\right]^{2+}(86.5) / \mathrm{HMS}, 15 \mathrm{ml}$ acetonitrile, $30 \mathrm{mmol}$ TBHP and $30 \mathrm{mmol}$ of benzyl alcohol, was refluxed for $4 \mathrm{~h}$, conversion of $35 \%$ was obtained. Then the reaction mixture was filtered and then filtrate solution was refluxed for next $4 \mathrm{~h}$ and conversion of $37 \%$ was obtained. For comparison, another experiment was carried out by refluxing of initial reaction mixture for 8 h without catalyst filtration, the results showed $49 \%$ conversion.

Therefore, these results demonstrate that the leaching of Mn complex from solid catalyst during liquid phase reaction is low and catalyst is stable and also indicating the homogeneous catalyst (Mn complex) have lower activity with respect to heterogeneous catalyst (Mn complex/HMS).

In recycling study, after each experiment, the catalyst was separated from the reaction mixture by filtration, washed with the solvent and dried carefully before using it in the subsequent run. The catalysts with different loading of $\mathrm{Mn}^{2+}$ were recycled for three times. The results are shown in figure 8 and it illustrates that, with increasing the loading of $\mathrm{Mn}^{2+}$ from $10.8-86.5 \mathrm{mg}$

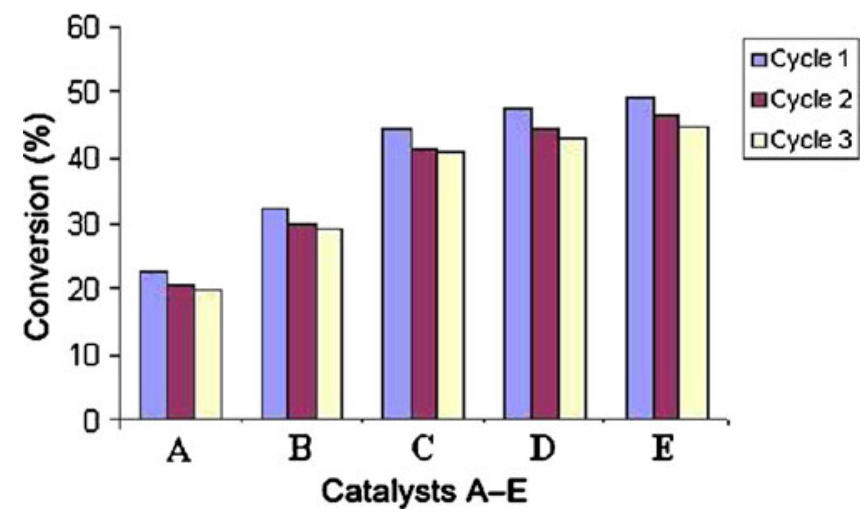

Figure 8. The effect of catalyst recycling. $\mathrm{A}=$ $\left[\mathrm{Mn}(\text { bipy })_{2}\right]^{2+}(10.8) / \mathrm{HMS} ; \mathrm{B}=\left[\mathrm{Mn}(\text { bipy })_{2}\right]^{2+}(21.6) / \mathrm{HMS}$; $\left.\mathrm{C}=\mathrm{Mn}(\text { bipy })_{2}\right]^{2+}(43.2) / \mathrm{HMS}, \mathrm{D}=\left[\mathrm{Mn}(\text { bipy })_{2}\right]^{2+}(64.7) /$ HMS; $\mathrm{E}=\left[\mathrm{Mn}(\text { bipy })_{2}\right]^{2+}(86.5) / \mathrm{HMS}$. Reaction condition: $0.2 \mathrm{~g}\left[\mathrm{Mn}(\mathrm{bipy})_{2}\right]^{2+} / \mathrm{HMS}$ catalyst; reflux temperature $\left(90^{\circ} \mathrm{C}\right)$ Alcohol $30 \mathrm{mmol}$; Oxidant $30 \mathrm{mmol} ; 15 \mathrm{~mL}$ acetonitrile; reaction time of a run $8 \mathrm{~h}$.
$\mathrm{Mn} / 1 \mathrm{~g}$ HMS, there is a 3-5\% loss of activity with lowering in conversion of benzyl alcohol (without any loss in selectivity). This indicates that catalysts are stable and therefore the reusability of catalyst was efficient.

\section{Conclusions}

The $\left[\mathrm{Mn}(\text { bipy })_{2}\right]^{2+} / \mathrm{HMS}$ sample is an active agent in catalysing the oxidation of benzyl alcohol with good conversion percentage and high selectivity by using TBHP as an oxidant. Only $0.2 \mathrm{~g}$ of the catalyst in mild conditions may be able to carry out the oxidation reaction successfully. This catalytic system in the polar protic solvents such as acetonitrile, gives the best conversion results. The activity of catalyst is a second order function with respect to the loading of $\mathrm{Mn}^{2+}$ ions in catalyst samples. In addition, alkyl peroxides prove to be very efficient and environmentally friendly oxidants since the by-products are only alkyl alcohols. It seems that, this kind of catalysis system is very active, selective and suitable for the oxidation of benzyl alcohol.

\section{References}

1. Sheldon R A and Kochi J K 1981 Metal-catalysed oxidation of organic compounds (New York: Academic Press)

2. Hudlicky M 1990 Oxidations in organic chemistry, ACS monograph series (Washington: American Chemical Society)

3. Chaudhari M P and Sawant S B 2005 Chem. Eng. J. 106 111

4. Hill C L and Baumstark A L 1988 Advances in oxygenated processes (London: JAI press Ltd.) vol. 1

5. Tsuruya S, Miyamoto H, Sakae T and Masai M $1980 \mathrm{~J}$. Catal. 64260

6. Sarmah P, Das B K, Phukan P 2010 Catal. Commun. 11 932

7. Tang Q, Gong X, Zhao P, Chen Y and Yang Y 2010 Appl. Catal. A 389101

8. Tang Q, Wu C, Qiao R, Chen Y and Yang Y 2011 Appl. Catal. A 403136

9. Bordoloi A, Sahoo S, Lefebvre F and Halligudi S B 2008 J. Catal. 259232

10. Chen Y, Lim H, Tang Q, Gao Y, Sun T, Yan Q and Yang Y 2010 Appl. Catal. A 38055

11. Du Z, Ma J, Ma H, Gao J and Xu J 2010 Green Chem. 12590

12. Maity P, Gopinath C S, Bhaduri S and Lahiri G K 2009 Green Chem. 11554

13. Hayashibara H, Nishiyama S, Tsuruya S and Masai M 1995 J. Catal. 153254

14. Kulkarni S J, Ramachandra Rao R, Subrahmanyam M, Rama Rao A V, Sarkany A and Guczi L 1996 Appl. Catal. A 13959 
15. Sumathi R, Johnson K, Vishwanathan B and Varadarajan T K 1998 Appl. Catal. A 17215

16. Dalal M K, Upadhyay M J and Ram R N 1999 J. Mol. Catal. A 142325

17. Choudhary V R, Chaudhari P A and Narkhede V S 2003 Catal. Commun. 4171

18. Stuchinskaya T L and Kozhevnikov I V 2003 Catal. Commun. 4417

19. Lingaiah N, Mohan Reddy K, Seshu Babu N, Narasimha Rao K, Suryanarayana I and Sai Prasad P S 2006 Catal. Commun. 7245

20. Choudhary V R, Dumbre D K, Narkhede V S and Jana S K 2003 Catal. Lett. 86(4) 229

21. Mahdavi V, Mardani M and Malekhosseini M 2008 Catal. Commun. 92201
22. Tanev P T, Chibwe M and Pinnavaia T J 1994 Nature 368321

23. Reddy J S, Liu P and Sayari A 1996 Appl. Catal. A: Gen. 1487

24. Alizadeh M, Farzaneh F and Ghandi M $2003 \mathrm{~J}$. Mol. Catal, A: Chem. 194283

25. Hodnett B K 2000 Heterogeneous catalytic oxidation (New York: John Wiley \& Sons, Ltd.)

26. Fu Zaihui, Liao Huiying, Xiong Donglu, Zhang Zehui, Jiang Yan and Yin Dulin 2007 Microporous Mesoporous Mater. 106298

27. Bosnich B 1968 J. Am. Chem. Soc. 90627

28. Crawford S M 1963 Spectrochim. Acta 19255

29. Moore W J and Pearson R G 1981 Kinetics and mechanism (New York: John Wiley \& Sons, Inc.) 